-ORIGINAL ARTICLE

Volume 13 Issue 12021

DOI: 10.21315/eimj2021.13.1.4

ARTICLE INFO

Submitted: $31-05-2020$

Accepted: 06-12-2020

Online: 31-03-2021

\section{Comparing Faculty Development Needs of Basic Sciences and Clinical Teachers During Major Curricular Reform at Prince Sattam Bin Abdulaziz Medical College in Saudi Arabia}

\author{
Amira Farghaly ${ }^{1,2}$ \\ ${ }^{1}$ Department of Medical Education, Faculty of Medicine, Suez Canal \\ University, Ismailia, EGYPT \\ ${ }^{2}$ Department of Basic Medical Sciences, College of Medicine, Prince \\ Sattam Bin Abdulaziz University, SAUDI ARABIA
}

To cite this article: Farghaly A. Comparing faculty development needs of basic sciences and clinical teachers during major curricular reform at Prince Sattam Bin Abdulaziz Medical College in Saudi Arabia. Education in Medicine Journal. 2021;13(1):31-41. https://doi.org/10.21315/eimj2021.13.1.4

To link to this article: https://oi.org/10.21315/eimj2021.13.1.4

\begin{abstract}
The required competencies of the medical graduates are changing, and by turn those of medical educators are changing as well. The aim of this study was to compare the faculty development (FD) needs of basic sciences and clinical teachers at the College of Medicine, Prince Sattam Bin Abdulaziz University during reforming of the curriculum to an integrated student-centred curriculum. This study is a descriptive cross-sectional study that included an online survey for faculty members to assess their FD needs and priorities. The survey questionnaire included questions about the experience of faculty members in teaching in integrated curricula, motivators to share in FD activities, preferred formats of FD activities, self-perceived competencies and needs in different areas of medical education, and selfperceived current commitment to the 12 roles of medical educators. Comparison between the basic sciences and the clinical teachers' perceived competencies, priorities and commitment to the roles of the medical teacher took place. Mann-Whitney U test was used to compare means. The results of the study showed that the highest self-perceived competencies of faculty members were in lecturing (mean $=4.25 \pm 0.99$ ) and constructing multiple choice questions (mean $=4.25 \pm 0.92$ ). Statistically significant differences were present between basic sciences and clinical teachers in designing integrated courses $(p=0.02)$ and clinical teaching $(p=0.03)$. Significant differences were also present in the perceived importance of certain topics in FD programmes, such as course design, blueprinting and simulation. The study concluded that there are differences between basic medical sciences and clinical teachers in the learning needs and the competencies, which should be taken into consideration during planning for $\mathrm{FD}$ activities.
\end{abstract}

Keywords: Needs assessment, Faculty development, Curricular reform

Amira Farghaly, Department of Basic Medical Sciences, College of Medicine, Prince Sattam Bin Abdulaziz University, P.O. box: 173, Al Kharj 11942, Saudi Arabia | Email: am.farghaly@psau.edu.sa 


\section{INTRODUCTION}

Among the expected challenges to medical educators in the $21 \mathrm{st}$ century are the changes in the healthcare systems and therefore the required competencies of the medical graduates and by turn of medical educators (1). New concepts are emerging in healthcare every day, such as patient involvement in care, interprofessional education and patient safety (2). These concepts would certainly reflect on the professional roles of doctors (3).

Medical school curricula have undergone major evolution worldwide as a result of placing increasing scrutiny on preparing medical school graduates for large volumes of clinical work (4). Integration, problem-based learning, communitybased education, elective courses and more systematic curriculum planning have been added to the tray of medical education (5). More emphasis is being made on selfdirected learning (6), with encouragement of students to take more responsibility for their own learning (7), in addition to encouragement of critical approach to knowledge rather than mere regurgitation of enormous amounts of material (8). At the end of the 20th century and the beginning of the 21 st century, many medical schools around the world conducted reform of their curricula towards problem-based learning and competency-based education (9).

Medical educators are responsible for teaching undergraduate students, training junior doctors and continuous professional development for doctors at all levels. They are usually a mix of university-employed academics (from medical or non-medical background), clinicians with academic titles and health practitioners employed solely by health service providers (10). In line with the changes in medical schools' curricula, the roles of the medical teacher are also changing, a thing that might cause unease among medical teachers who are familiar with traditional teaching methods only.
There is no consensus on the core competencies of an excellent medical educator (11). Some authors described the roles of the medical educator as a broad spectrum of roles that included teaching, curriculum planning and evaluation, innovation and research with emphasis on reflective practice throughout this array of roles (12). Some others simply devised the roles of the medical educator as teaching, research and management (11). In spite of the apparent difficulty in defining the exact roles of the medical educator/teacher, Harden and Crosby (5) developed a structured role model framework to explain the different roles of the medical teacher, which is expected to fulfill throughout their work in an attempt to build a benchmark for medical teachers. This model has gained popularity among medical schools around the world and used as a guide for medical educators. The model is also used in the assessment of the needs for staff to implement a curriculum, in the appointment and promotion of teachers and in the organisation of a staff development programme.

Many frameworks were developed later by national bodies in different countries that describe the standard roles and practices of the medical educator, such as the Professional Standards of Medical Educators in the UK (13), the five core educator roles by the Association of American Medical Colleges (AAMC) (14) and the University Teaching Qualification certificate in the Netherlands (15). Many medical schools even included teaching practices in their undergraduate curricula (3).

Faculty development (FD) programmes aim at initiating and sustaining change (16). Change is not only on the professional level of the individual doctor, but it can be at the institutional level if FD programmes were effectively planned and implemented (17). FD programmes should be guided by knowing what the core competencies of medical educators are (18), and of course, by their learning needs. Their focus should 
not only be on teaching, but also on other aspects that can serve medical educators in their roles, such as planning the curriculum, management and leadership, and educational administration and scholarship (19).

In order to effectively plan for FD activities, the learning needs of faculty members should be sought. This would render the FD activities more beneficial to faculty members as the training would be tailored to their needs (20). Usually, there is a lack of systematic approaches for needs assessment of faculty members (21). Needs assessment is usually conducted to help in setting the goals of FD programmes, deciding on the content and the priorities of training, deciding on the format of training and ensuring motivation of faculty members (22).

There are many ways to assess the learning needs of faculty members. One of these methods is to evaluate their competencies against known criteria and frameworks. Another method can allow them to identify their own inadequacies. It would be of great help to this process if the culture inside the institution encourages self-assessment and self-reflection (16).

Since its establishment in 2008, the College of Medicine, Prince Sattam Bin Abdulaziz University has adopted a traditional, discipline-based curriculum in which a large amount of time dedicated to conventional lectures. The college is reforming its undergraduate medical education programme, so that it would become student-centred, integrated and problem-based. The need for reforming was based on conformance to the national and international approaches to medical education in the 21 st century, conformance to quality and accreditation standards (23), and adoption of continuous quality improvement initiatives.

This study is conducted in order to guide the development of a comprehensive FD plan that supports the implementation of the curricular reform activities. The aim of this study is to compare the FD needs of basic sciences and clinical teachers in order to effectively plan for FD activities. The study is expected to answer the question "should FD activities be planned differently for basic sciences teachers than for clinical teachers?"

\section{METHODOLOGY}

\section{Study Design}

This is a descriptive cross-sectional study that was held at the College of Medicine, Prince Sattam Bin Abdulaziz University from May to July 2018. It comprised an online self-administered survey for faculty members to assess their learning needs with the initiation of the new curriculum and the addition of new teaching and assessment methods. The survey was posted to faculty members on https://www.jotform.com and the responses were anonymous.

\section{Participants}

The target population was the faculty members affiliated to College of Medicine, Prince Sattam Bin Abdulaziz University. The total number of faculty affiliated to the college is 100 members. In this study, we excluded faculty members in different kinds of leaves and sabbaticals $(50 \%)$. Therefore, a comprehensive sample was taken and included 50 faculty members to whom the survey was sent.

\section{Data Collection Instrument}

A self-administered online survey questionnaire was designed for the purpose of the study. It was validated for face and content validity by three medical education experts. The survey was divided into four sections: general information, existing competencies, FD needs and benchmarking against the 12 roles of medical educators of the role model framework developed by Harden and Crosby (5). The items included in the general information 
section were data about specialty, previous training in medical education and previous experience in problem-based learning (PBL) curricula. The items included in the existing competencies section were measuring the self-perceived competencies of faculty members in different topics of medical education, especially those needed for the establishment and functioning of the new curriculum. As for the section that comprising FD needs, it included items measuring the perceived need for training in different medical education topics. This section also includes questions about the preferred formats for FD and about the different motivators to share in FD activities. The section under benchmarking against the 12 roles included items about the importance of each of the medical educator's role for the new curriculum, as well as the current level of commitment of faculty members to the 12 roles. The questions of the survey were mainly on a 5-point Likert scale.

\section{Data Analysis}

Quantitative data gathered from the survey was coded and entered on SPSS version 20, then interpreted in the form of frequencies, means and standard deviations. Cronbach alpha was performed to test the reliability of the survey items. Mann-Whitney $U$ test was used to compare the responses of basic sciences and clinical teachers in many aspects, such as their commitment to their roles as medical educators, their perceived competence in medical education, and their preference of FD topics. Mann-Whitney U test was selected as all compared variables were ordinal in nature and the test of normality showed non-normal distribution of results in all variables. Results were considered statistically significant at $95 \%$ confidence level $(p<0.05)$.

\section{Ethical Considerations}

The descriptive survey was in an online format that guarantees the anonymity of responses and since the survey targeted faculty members and not a vulnerable group, no consent was needed, and their answer to the questionnaire was considered as an approval. The goal of the research was explicitly mentioned at the outset. An information sheet was sent to the participants before data collection to familiarise them with the nature of research, their roles and the ethical considerations. Institutional Review Board (IRB) approval to conduct the study was obtained from Prince Sattam Bin Abdulaziz University.

\section{RESULTS}

The questionnaire used to assess the learning needs of faculty members showed a high internal consistency (Cronbach's alpha $=0.975)$. Thirty-one faculty members responded with a response rate of $62 \%$. Among them, 12 members (38.7\%) were from the basic medical sciences department and 19 (61.3\%) from the clinical department. The respondents were 4 professors (12.9\%), 3 associate professors $(9.7 \%), 18$ assistant professors $(58.1 \%)$, and 6 lecturers (19.4\%). Only 20\% of respondents have previously taught in integrated PBL curricula.

As regard, the previous training in medical education and the previous experience in PBL curricula teaching, 22 faculty members $(71 \%)$ received previous training in medical education and only 9 faculty members (29\%) previously taught in a PBL curriculum. As shown in Table 1, the preferred formats of FD activities were workshops, certified degrees, on-campus courses and seminars. As shown in Table 2, the motivator to participate in FD activities included mainly improving teaching practices, learning new concepts and selfsatisfaction. 
Table 1: Comparison between the preference of basic sciences teachers and clinical teachers regarding FD formats

\begin{tabular}{lccccc}
\hline \multirow{2}{*}{ Items } & \multicolumn{2}{c}{ Basic sciences teachers } & \multicolumn{2}{c}{ Clinical teachers } & \multirow{2}{*}{-value } \\
\cline { 2 - 4 } & Mean & SD & Mean & SD & \\
\hline Seminars & 4.08 & 0.90 & 4.00 & 1.20 & 0.91 \\
Workshops & 4.16 & 0.93 & 4.52 & 0.61 & 0.28 \\
On-campus courses & 3.58 & 0.90 & 4.36 & 0.83 & $0.01^{*}$ \\
E-courses & 3.25 & 0.86 & 4.15 & 0.89 & $0.01^{*}$ \\
Blended courses & 3.16 & 0.85 & 4.16 & 0.61 & $0.02^{*}$ \\
Flipped classrooms & 3.00 & 0.73 & 3.84 & 0.89 & $0.01^{*}$ \\
Conferences & 3.58 & 1.16 & 4.00 & 1.05 & 0.31 \\
Certified degrees & 4.16 & 1.11 & 4.36 & 0.76 & 0.78 \\
\hline
\end{tabular}

Note: 1 = Not at all interesting; 2 = Slightly interesting; 3 = Moderately interesting; 4 = Quite interesting; 5 = Extremely interesting. * ${ }^{*}$ tatistically significant at $95 \%$ confidence level.

Table 2: Comparison between the motivators for basic sciences teachers and clinical teachers to participate in FD activities

\begin{tabular}{lccccc}
\hline \multirow{2}{*}{ Items } & \multicolumn{2}{c}{ Basic sciences teachers } & \multicolumn{2}{c}{ Clinical teachers } & \multirow{2}{*}{ p-value } \\
\cline { 2 - 4 } & Mean & SD & Mean & SD & \\
\hline Certification & 4.18 & 0.98 & 4.10 & 0.73 & 0.59 \\
Promotion & 4.08 & 1.56 & 4.31 & 0.88 & 0.88 \\
Acknowledgement & 4.33 & 0.65 & 4.00 & 1.08 & 0.48 \\
Learning new concepts & 4.41 & 0.78 & 4.68 & 0.58 & 0.32 \\
Improving teaching & 4.50 & 0.52 & 4.73 & 0.56 & 0.13 \\
practices & & & & & \\
Self-satisfaction & 4.50 & 0.67 & 4.57 & 0.60 & 0.75 \\
$\begin{array}{l}\text { Acquisition of continuing } \\
\text { medical education hours }\end{array}$ & 3.75 & 0.98 & 4.36 & 0.76 & 0.06 \\
\hline
\end{tabular}

Note: $1=$ Strongly disagree; 2 = Disagree; $3=$ Neutral $; 4=$ Agree; $5=$ Strongly agree.

Results of the inquiry about the content of training in the FD programmes showed that the most preferred topics were clinical skills teaching, student motivation, quality assurance in medical education and course evaluation. As shown in Table 3, the comparison between the basic medical sciences department and the clinical department concerning perceived importance of FD topics showed that the clinical department had higher means in all items. Some of these items showed statistically significant differences.
Table 4 shows the highest perceived competencies among faculty members were in lecturing, constructing multiple choice questions (MCQs), student motivation and constructing stations for performance assessments (objective structured clinical exam [OSCE] and objective structured practical exam [OSPE]). Comparison between the basic medical sciences department and the clinical department in the perceived competencies showed statistically significant differences in designing integrated courses, clinical skills teaching and designing simulation sessions. 
Concerning the perception of faculty members about their current commitment to the 12 roles of the medical educator, Table 5 shows that the highest perceived competencies were the roles of lecturer in classroom, learning facilitator and planner of formal exams. Comparison between the basic medical sciences department and the clinical department with the current commitment to the 12 roles of medical educators did not show any statistically significant difference except for the role of lecturer in clinical/practical setting $(p=0.009)$, where the clinical teachers reported a higher mean. As regard, the perceived importance of the 12 roles for the new curriculum showed that all roles were considered important. The most important roles were lecturer in clinical or practical setting, lecturer in classroom and course organiser $($ mean $=4.32 \pm 0.97$ ). Comparison between the basic medical sciences department and the clinical department in the perceived competencies showed statistically significant differences in designing integrated courses, clinical skills teaching and designing simulation sessions.

Table 3: Comparison of opinions of basic medical sciences teachers and clinical teachers concerning the importance of topics to be included in the FD activities $(n=31)$

\begin{tabular}{|c|c|c|c|c|c|}
\hline \multirow{2}{*}{ Items } & \multicolumn{2}{|c|}{ Basic sciences teachers } & \multicolumn{2}{|c|}{ Clinical teachers } & \multirow{2}{*}{$p$-value } \\
\hline & Mean & SD & Mean & SD & \\
\hline Problem construction & 4.3333 & 0.49237 & 4.4211 & 0.69248 & 0.524 \\
\hline PBL process & 4.2500 & 0.62158 & 4.2632 & 0.80568 & 0.826 \\
\hline $\begin{array}{l}\text { Facilitating small group } \\
\text { discussions }\end{array}$ & 4.2500 & 0.62158 & 4.4737 & 0.84119 & 0.223 \\
\hline Integration in medical education & 4.1667 & 0.83485 & 4.4211 & 0.76853 & 0.374 \\
\hline Lecturing & 4.4167 & 0.79296 & 4.3158 & 0.82007 & 0.736 \\
\hline Writing learning outcomes & 4.0833 & 0.66856 & 4.2105 & 0.91766 & 0.472 \\
\hline Course design & 4.0833 & 0.79296 & 4.6316 & 0.76089 & $0.032^{*}$ \\
\hline Clinical skills teaching & 4.1667 & 0.71774 & 4.8421 & 0.50146 & $0.002^{*}$ \\
\hline Simulation & 3.6667 & 0.77850 & 4.4737 & 0.69669 & $0.008^{*}$ \\
\hline Portfolios & 3.3636 & 0.50452 & 4.1111 & 0.90025 & $0.014^{*}$ \\
\hline $\begin{array}{l}\text { Blueprinting for written } \\
\text { assessment }\end{array}$ & 3.7500 & 0.75378 & 4.5789 & 0.60698 & $0.004^{*}$ \\
\hline $\begin{array}{l}\text { Constructing items for written } \\
\text { tests }\end{array}$ & 3.8182 & 0.60302 & 4.5263 & 0.61178 & $0.006^{*}$ \\
\hline Planning for OSPE/OSCE & 3.8333 & 0.83485 & 4.6316 & 0.59726 & $0.008^{*}$ \\
\hline Blueprinting for OSPE/OSCE & 3.7500 & 0.75378 & 4.6842 & 0.58239 & $0.001^{*}$ \\
\hline Designing OSPE/OSCE stations & 3.7500 & 0.96531 & 4.6316 & 0.59726 & $0.007^{*}$ \\
\hline Item analysis for MCQs & 3.6667 & 0.88763 & 4.4737 & 0.77233 & $0.013^{*}$ \\
\hline Psychometrics for OSPE/OSCE & 3.5833 & 0.79296 & 4.4211 & 0.76853 & $0.008^{*}$ \\
\hline Mentoring & 3.6667 & 0.88763 & 4.2222 & 0.80845 & 0.098 \\
\hline Online course management & 3.5000 & 0.67420 & 4.0526 & 0.97032 & $0.050^{*}$ \\
\hline Student motivation & 4.2500 & 0.86603 & 4.6316 & 0.68399 & 0.173 \\
\hline Course evaluation & 4.1667 & 0.83485 & 4.5789 & 0.60698 & 0.153 \\
\hline Quality assurance & 4.0000 & 0.85280 & 4.7368 & 0.56195 & $0.009^{*}$ \\
\hline
\end{tabular}


Table 4: Comparison of perceived competencies of basic medical sciences teachers and clinical teachers in different topics of medical education $(n=31)$

\begin{tabular}{|c|c|c|c|c|c|}
\hline \multirow{2}{*}{ Items } & \multicolumn{2}{|c|}{ Basic sciences teachers } & \multicolumn{2}{|c|}{ Clinical teachers } & \multirow{2}{*}{$p$-value } \\
\hline & Mean & SD & Mean & SD & \\
\hline Constructing educational problems & 3.5000 & 0.52223 & 2.9474 & 1.02598 & 0.087 \\
\hline Designing integrated courses & 3.4167 & 0.90034 & 2.5263 & 1.26352 & $0.023^{*}$ \\
\hline Facilitating small group discussions & 4.0000 & 1.20605 & 3.5263 & 0.96427 & 0.118 \\
\hline Lecturing & 4.4167 & 1.24011 & 4.1579 & 0.83421 & 0.158 \\
\hline Writing learning outcomes & 3.9167 & 1.08362 & 3.7368 & 1.97580 & 0.546 \\
\hline Clinical teaching & 3.4167 & 1.24011 & 4.2632 & 1.04574 & $0.034^{*}$ \\
\hline Designing simulation session & 2.3333 & 1.07309 & 3.2632 & 1.04574 & $0.019^{*}$ \\
\hline Evaluating students' portfolios & 3.5455 & 1.03573 & 3.4211 & 0.96124 & 0.671 \\
\hline Preparing blueprints for exams & 3.5000 & 1.08711 & 3.3158 & 1.29326 & 0.673 \\
\hline Constructing MCQs & 4.3333 & 1.15470 & 4.2105 & 0.78733 & 0.313 \\
\hline Constructing supply items & 3.8333 & 1.40346 & 4.0000 & 0.94281 & 0.965 \\
\hline Designing OSPE/OSCE stations & 3.9167 & 1.24011 & 4.0526 & 0.84811 & 0.947 \\
\hline Item analysis for MCQs & 2.8333 & 1.19342 & 3.1053 & 1.28646 & 0.513 \\
\hline $\begin{array}{l}\text { Interpreting psychometrics of OSPE/ } \\
\text { OSCE }\end{array}$ & 2.9167 & 1.16450 & 3.0526 & 1.26814 & 0.717 \\
\hline Mentoring students & 3.9167 & 1.16450 & 4.0000 & 0.81650 & 0.881 \\
\hline Course evaluation & 3.8333 & 1.02986 & 3.5789 & 0.96124 & 0.265 \\
\hline Student motivation & 4.3333 & .650134 & 4.1053 & 0.80930 & 0.458 \\
\hline Course management on blackboard & 3.1667 & 1.33712 & 3.1111 & 1.32349 & 0.914 \\
\hline Quality assurance & 3.3636 & 1.12006 & 3.0526 & 1.07877 & 0.435 \\
\hline e-learning & 3.0833 & 0.79296 & 3.0526 & 1.22355 & 0.882 \\
\hline
\end{tabular}

Note: 1 = Not competent at all; 2 = Slightly competent; 3 = Moderately competent; 4 = Quite competent; 5 = Extremely competent. "Statistically significant at $95 \%$ confidence level.

Table 5: Comparison of current commitment to the 12 roles of medical educators between faculty members affiliated to the basic medical sciences and clinical sciences $(n=31)$

\begin{tabular}{lccccc}
\hline \multirow{2}{*}{ 12 roles of medical educators } & \multicolumn{2}{c}{ Basic sciences teachers } & \multicolumn{2}{c}{ Clinical teachers } & \multirow{2}{*}{$\boldsymbol{p}$-value } \\
\cline { 2 - 5 } & Mean & SD & Mean & SD & \\
\hline Lecturer in classroom & 4.5000 & 0.90453 & 4.4737 & 0.69669 & 0.673 \\
Lecturer in clinical or practical setting & 3.5000 & 1.24316 & 4.5263 & 0.69669 & $0.009^{*}$ \\
On-job role model & 3.6667 & 0.77850 & 3.4211 & 1.12130 & 0.688 \\
Teaching role model & 4.0000 & 0.95346 & 3.6316 & 0.89508 & 0.237 \\
Mentor/personal adviser & 3.8333 & 1.02986 & 3.7895 & 0.85498 & 0.914 \\
Learning facilitator & 4.1667 & 0.71774 & 3.5556 & 0.92178 & 0.066 \\
Planner of formal exams & 3.9167 & 0.99620 & 4.0526 & 0.70504 & 0.795 \\
Curriculum evaluator & 3.5833 & 0.90034 & 3.4211 & 1.30451 & 0.932 \\
Curriculum planner & 3.6667 & 1.15470 & 3.3684 & 1.38285 & 0.717 \\
\hline
\end{tabular}


Table 5: (continued)

\begin{tabular}{lccccc}
\hline \multirow{2}{*}{12 roles of medical educators } & \multicolumn{2}{c}{ Basic sciences teachers } & \multicolumn{2}{c}{ Clinical teachers } & \multirow{2}{*}{$\boldsymbol{p}$-value } \\
\cline { 2 - 5 } & Mean & SD & Mean & SD & \\
\hline Course organiser/coordinator & 4.0000 & 1.04447 & 3.7368 & 1.24017 & 0.624 \\
Producer of study guides & 4.0000 & 1.04447 & 3.5263 & 1.38918 & 0.399 \\
Developer of learning resource materials & 3.5833 & 1.16450 & 3.2632 & 1.32674 & 0.686 \\
\hline
\end{tabular}

Note: 1 = None; 2 = Little; 3 = Some; 4 = Considerable; 5 = Great. "Statistically significant at 95\% confidence level.

\section{DISCUSSION}

This study was conducted to compare the FD needs of basic sciences teachers and clinical teachers during reforming of the curriculum from a traditional teachercentred curriculum to an integrated, problem-based, student-centred curriculum, in order to guide the development of a comprehensive FD programme that is tailored to those needs. Tailoring the FD programmes to the faculty needs could help with motivating them to participate in the programme and maximise their benefit from it (24).

The results of the study showed that the highest perceived competencies among faculty members were related to the traditional teaching practices, such as lecturing, constructing MCQs and conducting performance assessments. This is consistent with the traditional curriculum that was run for 10 academic years in the college. In a study held in Turkey that assessed the self-perceived competencies before FD programme conduction, a big proportion of respondents perceived their teaching skills as excellent (25). $\mathrm{Ng}$ states that "little is known about what factors can motivate teachers to engage in professional learning in a meaningful way" (26). In the current study, motivators for participating in FD activities were mainly internal motivators. This is consistent with the results of a study that was held in Ireland (27), in which personal choice for continuous professional development (CPD) activities among school teachers was the most cited motivator for participating in CPD programmes.
From the point of view of faculty members, all medical educational concepts and topics suggested in the survey were considered important, with varying degrees. Similar results were also shown in another study where faculty members, even the experienced ones, reported the need to improve in most aspects of medical education (21). In the current study, clinical teachers were more interested in many more topics than basic sciences teachers. This would be beneficial during planning for FD as to make special focused sessions for clinicians addressing these topics.

There exists different formats for $\mathrm{FD}$ in the literature such as workshops, seminars, degree programmes, mentorship, peercoaching and communities of practice $(18,20)$. In the current study, the preferred formats of FD activities were mainly from the conventional formats, such as workshops, certified degrees, training courses and seminars. The innovative formats to $\mathrm{FD}$, such as the flipped classrooms and blended courses did not gain much popularity among the faculty members; perhaps because the change would then be overwhelming, with reforming of the curriculum and also FD formats. These results would inform the selection of FD formats, at least during the early phase of the FD programme until the faculty members are familiarised and comfortable with the new curriculum, then new FD formats can be added.

It is well known that one of the success factors for $F D$ is the commitment of faculty members in teaching (28). It was important to measure the self-perceived commitment of faculty members to the 
roles of the medical teacher. Therefore, one of the famous frameworks for the roles of the medical teacher was used to measure this commitment. It was also important to obtain the opinions of faculty members on the roles most needed for the new curriculum. This would help them perceive the gaps in competencies that they needed to work on. In this study, faculty members felt more competent as lecturers and students assessors, which is expected in traditional curricula. They felt less competent in the roles of curriculum planner and evaluator, and producer of learning materials. The differences between basic sciences teachers and clinical teachers were not statistically significant. These competencies therefore will be focused on in the FD activities for all teachers.

Many studies addressed evaluation of FD activities for participants that included a mix of clinicians, nurses, basic sciences teachers and health administrators. However, none of them compared the needs among professions. The current study is expected to add to the knowledge base about whether different groups of teachers have different needs and whether this should be taken into consideration during planning for FD programmes.

\section{LIMITATIONS}

This study has several limitations. Only "self-perceived" competencies opinions from the faculty members were sought. Other stakeholders' opinions such as the students and the patients would have added to the assessment of faculty members' competencies and current commitments. Also, the generalisability of the study is difficult to attain due to several reasons such as the small sample size. Besides, the fact that the study was performed in a specific situation, which is in curriculum reform.

\section{CONCLUSION}

It is obvious that curricular reform should be accompanied by a structured FD programme that is tailored to the needs of the faculty members and their expected roles. Basic medical sciences teachers may have different competencies and priorities in FD than clinical teachers. Therefore, it is important to tailor the programme to the needs of both types of teachers. It is now established that FD is essential during curricular reform. What is uncommonly found in the literature is whether there should be a different FD activities for basic sciences teachers and clinical teachers. This is yet an area to be further studied.

\section{REFERENCES}

1. Weinberger $\mathrm{S}$. The medical educator in the 21st century: a personal perspective. Trans Am Clin Climatol Assoc. 2009;120:239-48

2. Hutchinson L. Challenges of training doctors in the new English NHS. BMJ. 2006;332(7556):1502-4. https://doi. org/10.1136/bmj.332.7556.1502

3. Bleakley A, Bligh J, Browne J. Medical education for the future: identity, power and location. Netherlands: Springer; 2011. https://doi.org/10.1007/978-90-481-9692-0

4. Brauer DG, Ferguson KJ. The integrated curriculum in medical education: AMEE guide no. 96. Med Teach. 2015;37:31222. https://doi.org/10.3109/014215 9X.2014.970998

5. Harden RM, Crosby JR. AMEE education guide no. 20: The good teacher is more than a lecturer - the twelve roles of the teacher. Med Teach. 2000;22(4):334-47. https://doi. org/10.1080/014215900409429 
6. Kaufman DM, Mann KV. Teaching and learning in medical education: how theory can inform practice. In: Swanwick T, editor. Understanding medical education: evidence, theory, and practice. 2nd ed. Oxford: WileyBlackwell; 2014. p. 7-30.

7. Rowntree D. Teaching through selfinstruction: how to develop open learning materials. London: Kogan Page; 1990.

8. Feather A, Fry H. Key aspects of teaching and learning in medicine and dentistry. In: Fry H, Ketteridge S, Marshall S, editors. A handbook for teaching and learning in higher education. 2nd ed. London: Kogan Page; 2003. p. 366-90.

9. Jolly BC. Faculty development for curricular implementation. In: Norman GR, van der Vleuten CPM, Newble DI, editors. International handbook of research in medical education. Netherlands: Springer; 2002. p. 950. https://doi.org/10.1007/97894-010-0462-6_35

10. Bartle E, Thistlethwaite J. Becoming a medical educator: motivation, socialisation and navigation. BMC Med Educ. 2014;14:110. https://doi.org/10.1186/14726920-14-110

11. Bligh JMA, Brice J. Further insights into the roles of the medical educator: the importance of scholarly management. Acad Med. 2009;84:1161-5. https://doi. org/10.1097/ACM.0b013e3181ace633

12. Steinert Y. Faculty development: on becoming a medical educator. Med Teach. 2012;34(1):74-6. https://doi.org/10.3109/01 42159X.2011.596588

13. World Federation for Medical Education [Internet]. UK: WFME. c2021 [cited 2016 Dec 10]. Professional standards. Available from: http://www.wfme.org
14. Simpson D, Fincher RME, Hafler JP, Irby DM, Richards BF, Rosenfeld GC, Viggiano TR. Advancing educators and education by defining the components and evidence associated with educational scholarship. Med Educ. 2007;41(10):1002-9. https://doi. org/10.1111/j.1365-2923.2007.02844.x

15. Irby DM, O'Sullivan PS. Developing and rewarding teachers as educators and scholars: remarkable progress and daunting challenges. Med Educ. 2018;52:58-67. https://doi.org/10.1111/medu.13379

16. McLean M, Cilliers F, Van Wyk JM. Faculty development: yesterday, today and tomorrow. AMEE guide no. 36. Med Teach. 2008;30:555-84. https://doi. org/10.1080/01421590802109834

17. Steinert Y, Cruess RL, Cruess SR et al. Faculty development as an instrument of change: a case study on teaching professionalism. Acad Med. 2007;82:105764. https://doi.org/10.1097/01.ACM.0000 285346.87708.67

18. Steinert Y. Developing medical educators: a journey, not a destination. In: Swanwick T, editor. Understanding medical education: evidence, theory and practice, 2nd ed. Oxford: Wiley-Blacwell; 2014. p. 456.

19. Steinert Y, Naismith L, Mann K. Faculty development initiatives designed to promote leadership in medical education. A BEME systematic review: BEME guide no. 19. Med Teach. 2012;34(6):483-503. https://doi.org/ 10.3109/0142159X.2012.680937

20. Steinert Y. Staff development. In: Dent J, Harden $R$, editors. A practical guide for medical teachers. Edinburgh: Elsevier; 2005. p. 390-418. 
21. Amin Z, Eng KH, Gwee M, Hoon TC, Rhoon KD. Addressing the needs and priorities of medical teachers through a collaborative intensive faculty development programme. Med Teach. 2006;28(1):85-8. https://doi.org/10.1080/01421590500314124

22. Grant J. Learning needs assessment: assessing the need. BMJ. 2002;324:156-9. https://doi.org/10.1136/bmj.324.7330.156

23. Education Evaluation Commission. Saudi Arabia qualification framework. EEC version 7. Saudi Arabia: National Commission for Academic Accreditation and Assessment; 2017.

24. Hewson MG. A theory-based faculty development program for clinicianeducators. Acad Med. 2000;75(5):498501. https://doi.org/10.1097/00001888200005000-00024
25. Bahar-Ozvaris Se, Aslan D, SahinHodoglugil N, Sayek I. A faculty development program evaluation: from needs assessment to long-term effects, of the teaching skills improvement program. Teach Learn Med. 2004;16(4):368-75. https://doi. org/10.1207/s15328015tlm1604_11

26. Ng CH. Do career goals promote continuous learning among practicing teachers? Teachers and Teaching: Theory and Practice. 2010;16(4):397-422. https:// doi.org/10.1080/13540601003754806

27. McMillan D, McConnell B, O'Sullivan H. Continuing professional development why bother? Perceptions and motivations of teachers in Ireland. Professional Development in Education. 2014; 42(1):118. https://doi.org/10.1080/19415257.2014. 952044

28. Elliott R. Faculty development curriculum: what informs it? Journal of Faculty Development. 2014;28(3):35-46. 